\title{
Association between induction of the self-management system for preventing readmission and disease severity and length of readmission in patients with heart failure
}

\author{
Eisaku Nakane ${ }^{1}$, Takao Kato ${ }^{2 *}$,, Nozomi Tanaka ${ }^{2}$,Tomoari Kuriyama ${ }^{1}$ Koki Kimura ${ }^{1}$, Shushi Nishiwaki ${ }^{1}$,
} Toka Hamaguchi', Yusuke Morita', Yuhei Yamaji', Yoshisumi Haruna', Tetsuya Haruna ${ }^{1}$ and Moriaki Inoko'

\begin{abstract}
Objective: We recently developed the self-management system using the HF points and instructions to visit hospitals or clinics when the points exceed the pre-specified levels. We found that the self-management system decreased the hospitalization for HF with an increase in unplanned visits and early intervention in the outpatient department. However, it is unclear whether we managed severe HF outpatients who should have been hospitalized. In this study, we aimed to compare HF severity in rehospitalized patients with regard to self-management system use.

Results: We retrospectively enrolled 306 patients (153 patients each in the system user and non-user groups) using propensity scores (PS). We compared HF severity and length of readmission in rehospitalized patients in both groups. During the 1-year follow-up period, 24 system users and 43 non-system users in the PS-matched cohort were hospitalized. There were no significant differences between the groups in terms of brain natriuretic peptide levels at readmission, maximum daily intravenous furosemide dose, percentage of patients requiring intravenous inotropes, duration of hospital stay and in-hospital mortality. These results suggest that the HF severity in rehospitalized patients was not different between the two groups.
\end{abstract}

Keywords: Self-care management, Heart failure, Readmission, Rehospitalization

\section{Introduction}

Self-care maintenance and management are necessary to prevent rehospitalizations for heart failure (HF). It is important for patients and caregivers to manage worsening HF [1]. However, it is difficult for patients and caregivers to conclude whether HF is worsening, indicating the need to see a doctor [2,3]. Therefore, we have developed a new system to make self-care management as easy

\footnotetext{
*Correspondence: tkato75@kuhp.kyoto-u.ac.jp

${ }^{2}$ Department of Cardiovascular Medicine, Graduate School of Medicine, Kyoto University, 54 Shogoin Kawahara-cho, Sakyo-ku, Kyoto 606-8507, Japan

Full list of author information is available at the end of the article
}

as possible [4]. The new HF self-care system provided HF "points" for weight and clinical symptoms, and the total scores were correlated with appropriate consultation times for both patients and healthcare providers [4]. The HF points for each component are as follows: 1 point, if there is at least one presenting HF symptom (dyspnea on exertion, edema, cough, and appetite loss); 3 points, if the body weight exceeds the set weight limit; 4 points, if the heart rate is $\geq 120$ beats per minute (bpm); and 5 points, if there is dyspnea at rest [4]. Patients with $3 \mathrm{HF}$ points were instructed to visit the nearest outpatient clinic within 1 week, and those with 4 HF points were instructed to visit their physician on the same or the next day because of possible worsening HF [4]. Since 
hospitalization was highly indicated for patients with $\geq 5$ points, they were instructed to visit the nearest emergency department [4]. Home and outpatient nursing staff can help patients in recognizing worsening HF and support them in receiving medical care [4]. We recently reported the benefits of this system using a propensity score (PS)-matched cohort [4]. The composite endpoint of all-cause mortality and HF hospitalization rate was significantly lower in system users after 1 year, primarily by reduction in the latter [4]. The usefulness of the new HF self-care system for preventing HF readmission was elucidated in the previous study [4]. The number of unscheduled outpatient visits and early interventions were higher in the user group [4]. However, it is unclear whether there were very severe HF outpatients who required hospitalization.

In this study, we aimed to compare HF severity and length of readmission between the same cohort of system and non-system users from our previous study. This is a post hoc sub-study of the previous study in which the cumulative incidence and risk for readmission were analyzed; however, the severity of HF was not assessed [4]. This study provided additional data on HF severity when the patients were re-hospitalized.

\section{Main text \\ Methods}

\section{Study design}

Among the 569 consecutive patients with HF admitted to Kitano Hospital, 275 and 294 patients were admitted between November 2011 and October 2013 (before system induction) and between November 2015 and
October 2017 (after system induction), respectively, and were subsequently matched using PS [4]. Clinical followup data from all patients were collected in October 2017. Data analysis was conducted in August 2020. In the present analysis, we compared HF severity in readmitted self-management system users and non-users in the PSmatched cohort and entire cohort (Fig. 1).

\section{Ethics}

The study protocol conformed to the ethical guidelines of the 1975 Declaration of Helsinki and was approved by the Institutional Review Board of Kitano Hospital (P190600100). The requirement of informed consent was waived because of the retrospective nature of the study. We disclosed all study details to the public using an optout method and clearly informed the patients of their right to refuse enrollment.

\section{Self-care management system}

In the self-care HF assessment sheet described elsewhere [4], the patients' weight and clinical symptoms are scored using "HF points". The appropriate consultation times based on the scores were clarified to both patients and healthcare providers, described detailed previously [4]. We introduced the system to patients hospitalized for HF through a team conference at the beginning of their admission and to the patients' cohabitants, nearby family members, caregivers, or nurses who can perform the assessment at least once a week for those who were unable to self-manage [4]. Early intervention was defined as escalation of oral and intravenous diuretics at

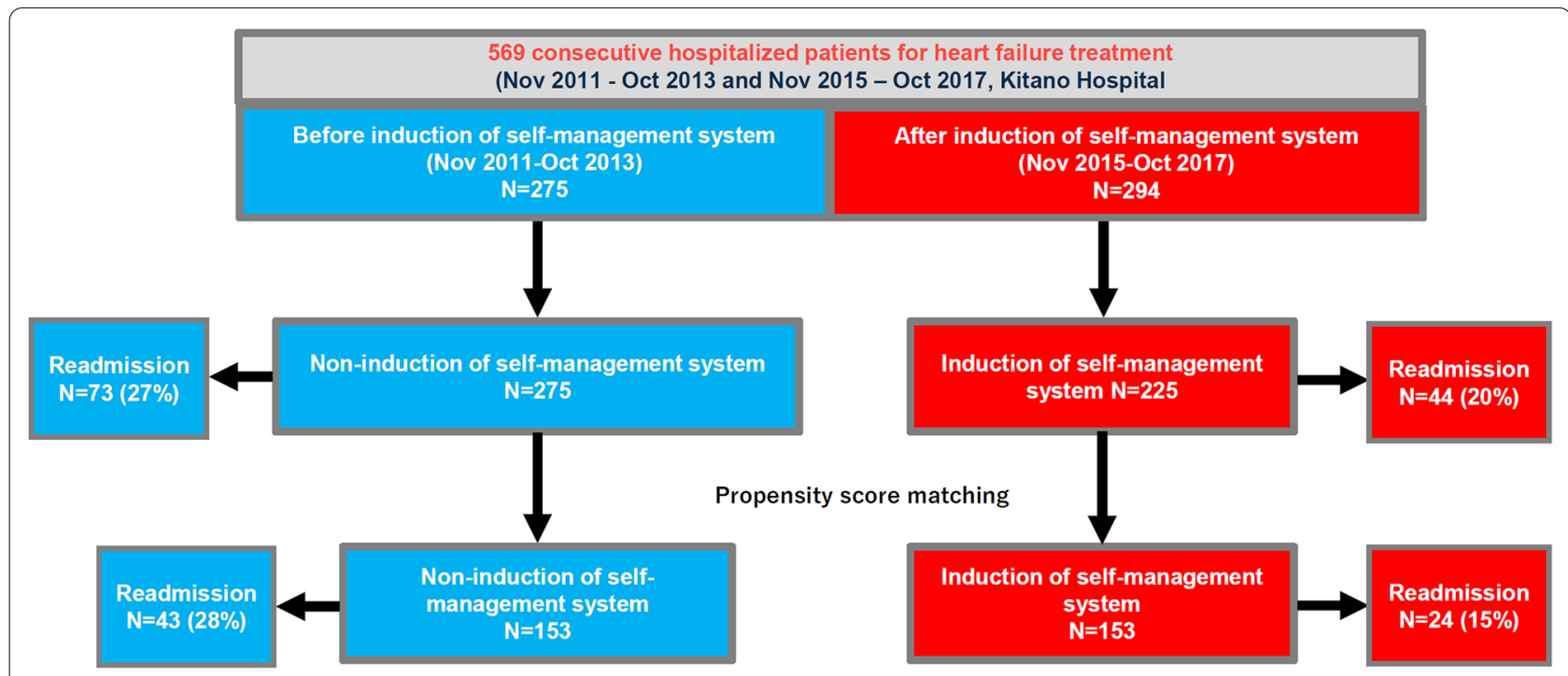

Fig. 1 Patient flowchart 
the outpatient department or shortened outpatient visit intervals without any hospitalization [4].

\section{Primary outcome measures}

The outcome measure in the current analysis was HF severity at readmission and length of readmission along with in-hospital mortality. HF severity in each group was evaluated using brain natriuretic peptide (BNP) levels at readmission, the maximum daily intravenous furosemide dose, and percentage of patients requiring intravenous inotrope. Data were collected retrospectively by chart review of each patient.

\section{Statistical analysis}

We used a PS-matched cohort study design to balance the baseline characteristics between system users and non-users as previously reported [4]. In brief, a logistic regression model was developed to make the PS with 19 baseline variables clinically relevant to the induction of the self-management program to balance the baseline characteristics associated with users and non-users. We matched the patients based on the estimated PS using greedy-matching technique (Fig. 1 and Additional file 1: Method). We then evaluated the differences between rehospitalized patients in the two groups. Categorical variables, expressed as numbers with percentages, were compared using the chi-square test, and continuous variables, expressed as means with standard deviations or medians with $25-75$ th percentiles (interquartile range: IQR), were compared using Student's t-test when normally distributed or the Wilcoxon rank-sum test when non-normally distributed. All statistical analyses were performed by physicians using JMP 14.0 (SAS Institute Inc., Cary, NC, USA) and SAS 9.4 (SAS Institute Inc., Cary, NC, USA). Statistical significance was set at $\mathrm{P}<0.05$.

\section{Results}

\section{Patient characteristics}

During the 1-year follow-up of the PS-matched cohort, $43(28 \%)$ system non-users and $24(15 \%)$ users were admitted due to HF [4]. There were no significant differences in patient characteristics between the groups (Table 1). Unplanned visits and early interventions were more often in the user group than in the non-user group (Table 1). The trend of the patients from the entire cohort was almost consistent with that of the PS-matched cohort (Table 1).

\section{Outcome measures}

The BNP levels at re-admission were not different between the groups (763 (IQR 516-1428) pg/ml in user group and 628 (IQR 435-1502) pg/ml in non-user group,
$P=0.707)$. The maximum daily dose of intravenous furosemide and percentages of patients requiring intravenous inotropes were not different between the group (Table 2). The readmission length was 15.5 (IQR 12.3-26) days in user group and 15 (IQR 11-27) days in non-user group, respectively $(\mathrm{P}=0.958)$. In-hospital mortality was $4.2 \%$ $(1 / 24)$ and $9.3 \%(4 / 43)$ in the user and non-user groups, respectively $(\mathrm{P}=0.647$; Table 2$)$.

\section{Discussion}

This study showed no significant difference in HF severity and length of readmission between self-care management system users and non-users. Using the system did not seem to cause that patients who were necessary to hospitalizations remain unhospitalized. Our results indicated that using a self-care management system may be clinically relevant as more frequent unplanned ambulatory visits and early interventions at outpatient clinics [4] prevented progression to very severe HF, in conjunction with the previous study [4].

Observational studies or sub-analyses of randomized trials have illustrated the impact of previous hospitalization on long-term mortality in patients with HF in Western [5-7] and Asian countries [8, 9]. The relationship with mortality and hospitalization was incremental [9]. The admission itself is related to adverse events [10], and functional decline was observed in patients hospitalized for HF [11]. Preventing rehospitalization is critical in the management of HF and maintenance of activities of daily living. The threshold for rehospitalization can be influenced by not only HF severity and presence of comorbidities but also differences in protocols among hospitals, physicians, or localities. After introducing the self-management system in our hospital [4], HF severity, length of readmission, and mortality rate did not differ between in system users and non-users. Overall, cumulative incidences of all-cause death in this PS-matched cohort were not different between the two groups, as reported previously [4]. Although the study was a retrospective study, with different timeframes between the users and nonusers, the threshold for rehospitalization at outpatient visits was not influenced by the self-management system use. However, we did not evaluate the overall in-hospital and outpatient costs, [12] thus further studies are warranted to address this issue. In conclusion, there was no significant difference in HF severity and length of readmission between self-care management system users and non-users.

\section{Limitations}

This study has several limitations. First, this study was retrospective study; thus, there were no pre-specified criteria for hospitalization nor the pre-specified treatment 
Table 1 Study population characteristics derived from the propensity score-matched and entire cohorts

\begin{tabular}{|c|c|c|c|c|c|c|}
\hline \multirow[t]{3}{*}{ Variables } & \multirow{2}{*}{\multicolumn{3}{|c|}{$\begin{array}{l}\text { Propensity score-matched cohort } \\
\text { Rehospitalized patients }\end{array}$}} & \multirow{2}{*}{\multicolumn{3}{|c|}{$\begin{array}{l}\text { Entire cohort } \\
\text { Rehospitalized patients }\end{array}$}} \\
\hline & & & & & & \\
\hline & $\begin{array}{l}\text { User } \\
(N=24)\end{array}$ & $\begin{array}{l}\text { Non-user } \\
(\mathrm{N}=43)\end{array}$ & $P$ value & $\begin{array}{l}\text { User } \\
(\mathrm{N}=44)\end{array}$ & $\begin{array}{l}\text { Non-user } \\
(\mathrm{N}=73)\end{array}$ & $P$ value \\
\hline \multicolumn{7}{|l|}{ Clinical characteristics } \\
\hline Age, years & $80.5[76-84]$ & $78.0[69-84]$ & 0.4874 & 80.5 [74-85] & 78.0 [71-83] & 0.216 \\
\hline Age $>80$ years & $13(54 \%)$ & $20(47 \%)$ & 0.615 & $23(52 \%)$ & $33(45 \%)$ & 0.567 \\
\hline Men & 15 (63\%) & $21(49 \%)$ & 0.317 & $22(50 \%)$ & $33(45 \%)$ & 0.851 \\
\hline \multicolumn{7}{|l|}{ Etiology } \\
\hline Ischemic heart disease & $8(33 \%)$ & $19(44 \%)$ & 0.444 & $14(32 \%)$ & $32(44 \%)$ & 0.243 \\
\hline Valvular heart disease & $11(46 \%)$ & $24(56 \%)$ & 0.457 & $21(48 \%)$ & $35(48 \%)$ & 1.000 \\
\hline Dilated cardiomyopathy & $1(4.2 \%)$ & $5(12 \%)$ & 0.408 & $3(6.8 \%)$ & $8(11 \%)$ & 0.532 \\
\hline \multicolumn{7}{|l|}{ Medical history } \\
\hline Atrial fibrillation or flutter & $12(50 \%)$ & $24(56 \%)$ & 0.799 & $21(48 \%)$ & $38(52 \%)$ & 0.705 \\
\hline Cardiac resynchronization therapy & $1(4.2 \%)$ & $3(7.0 \%)$ & 1.000 & $3(6.8 \%)$ & $4(5.5 \%)$ & 1.000 \\
\hline Implantable cardioverter defibrillator & $0(0 \%)$ & $0(0 \%)$ & 1.000 & $2(4.6 \%)$ & $0(0.0 \%)$ & 0.139 \\
\hline Diabetes mellitus & $9(38 \%)$ & $12(28 \%)$ & 0.426 & $14(32 \%)$ & $24(33 \%)$ & 1.000 \\
\hline Prior stroke & $6(25 \%)$ & $13(30 \%)$ & 0.780 & $9(20 \%)$ & $18(25 \%)$ & 0.657 \\
\hline Chronic obstructive lung disease & $6(25 \%)$ & $4(9.3 \%)$ & 0.149 & $10(23 \%)$ & $6(8.2 \%)$ & 0.049 \\
\hline Malignancy & 7 (29\%) & $5(12 \%)$ & 0.099 & $10(23 \%)$ & $13(18 \%)$ & 0.632 \\
\hline Dementia & $2(8.3 \%)$ & $3(7.0 \%)$ & 1.000 & $8(18 \%)$ & $4(5.5 \%)$ & 0.055 \\
\hline \multicolumn{7}{|l|}{ Vital signs at initial admission } \\
\hline Systolic blood pressure, $\mathrm{mmHg}$ & $121 \pm 27.1$ & $113 \pm 18.7$ & 0.347 & $118 \pm 25.8$ & $115 \pm 20.7$ & 0.782 \\
\hline Diastolic blood pressure, $\mathrm{mmHg}$ & $65.9 \pm 14.2$ & $63.4 \pm 13.6$ & 0.431 & $65.8 \pm 13,1$ & $64.3 \pm 14.1$ & 0.451 \\
\hline Heart rate, bpm & $70.4 \pm 10.6$ & $73.6 \pm 12.1$ & 0.364 & $71.3 \pm 11.9$ & $74.1 \pm 12.2$ & 0.242 \\
\hline \multicolumn{7}{|l|}{ Tests at initial admission } \\
\hline Left ventricular ejection fraction (LVEF), \% & $44.0 \pm 14.8$ & $44.7 \pm 17.8$ & 0.759 & $41.9 \pm 14.6$ & $45.6 \pm 16.3$ & 0.204 \\
\hline LVEF $<40 \%$ & $9(38 \%)$ & $22(51 \%)$ & 0.317 & $18(41 \%)$ & $32(44 \%)$ & 0.848 \\
\hline Estimated glomerular filtration rate (GFR), $\mathrm{mL} / \mathrm{min} / 1.73 \mathrm{~m}^{2}$ & $34[22-41]$ & $30[16-53]$ & 0.901 & $33[21-41]$ & $26[16-48]$ & 0.648 \\
\hline Estimated GFR $<30 \mathrm{~mL} / \mathrm{min} / 1.73 \mathrm{~m}^{2}$ & $11(46 \%)$ & $21(49 \%)$ & 1.000 & $20(45 \%)$ & $38(52 \%)$ & 0.568 \\
\hline Serum albumin $<3.5 \mathrm{~g} / \mathrm{dL}$ & $4(17 \%)$ & $6(14 \%)$ & 0.737 & $7(16 \%)$ & $13(18 \%)$ & 1.000 \\
\hline Hemoglobin, g/dL & $12[10-13]$ & $11[10-12]$ & 0.374 & $11[9.7-13]$ & $11[9.3-12]$ & 0.095 \\
\hline Hemoglobin $<13 \mathrm{~g} / \mathrm{dL}$ & $17(71 \%)$ & $39(91 \%)$ & 0.046 & $33(75 \%)$ & 69 (94\%) & 0.004 \\
\hline \multicolumn{7}{|l|}{ Concomitant treatment } \\
\hline$\beta$ blockers & 17 (71\%) & $27(63 \%)$ & 0.597 & $29(66 \%)$ & $41(56 \%)$ & 0.335 \\
\hline $\begin{array}{l}\text { Angiotensin converting enzyme inhibitors or angiotensin } \\
\text { receptor blockers }\end{array}$ & $16(67 \%)$ & $35(81 \%)$ & 0.234 & $33(75 \%)$ & $52(71 \%)$ & 0.831 \\
\hline Aldosterone antagonists & $12(50 \%)$ & $19(44 \%)$ & 0.799 & $24(55 \%)$ & $31(42 \%)$ & 0.252 \\
\hline Loop diuretics & $21(88 \%)$ & $36(84 \%)$ & 1.000 & $40(91 \%)$ & $60(82 \%)$ & 0.280 \\
\hline Thiazides & $4(17 \%)$ & $9(21 \%)$ & 0.757 & $8(18 \%)$ & $14(19 \%)$ & 1.000 \\
\hline Tolvaptan & $4(17 \%)$ & $5(12 \%)$ & 0.711 & $19(43 \%)$ & $5(6.9 \%)$ & $<0.001$ \\
\hline Inotropic agents & $4(17 \%)$ & $4(9.3 \%)$ & 0.443 & $5(11 \%)$ & $7(9.6 \%)$ & 0.762 \\
\hline Statins & $10(42 \%)$ & $17(40 \%)$ & 1.000 & $18(41 \%)$ & $29(40 \%)$ & 1.000 \\
\hline Calcium antagonists & $9(38 \%)$ & $14(33 \%)$ & 0.790 & $15(34 \%)$ & $31(42 \%)$ & 0.436 \\
\hline Multiple heart failure readmission (> 3times) & $6(25 \%)$ & $5(12 \%)$ & 0.182 & $11(25 \%)$ & $9(12 \%)$ & 0.127 \\
\hline First heart failure admission & $12(50 \%)$ & $26(60 \%)$ & 0.449 & $20(45 \%)$ & $41(56 \%)$ & 0.340 \\
\hline Living alone & $5(21 \%)$ & $11(26 \%)$ & 0.770 & $13(30 \%)$ & $15(21 \%)$ & 0.275 \\
\hline \multicolumn{7}{|l|}{ Unplanned ambulatory visits after initial admission } \\
\hline No visit & $2(8 \%)$ & $5(12 \%)$ & 0.021 & $5(11 \%)$ & $10(14 \%)$ & 0.009 \\
\hline One time & $15(63 \%)$ & $37(86 \%)$ & & $25(58 \%)$ & $58(80 \%)$ & \\
\hline
\end{tabular}


Table 1 (continued)

\begin{tabular}{|c|c|c|c|c|c|c|}
\hline \multirow[t]{3}{*}{ Variables } & \multirow{2}{*}{\multicolumn{3}{|c|}{$\begin{array}{l}\text { Propensity score-matched cohort } \\
\text { Rehospitalized patients }\end{array}$}} & \multirow{2}{*}{\multicolumn{3}{|c|}{$\begin{array}{l}\text { Entire cohort } \\
\text { Rehospitalized patients }\end{array}$}} \\
\hline & & & & & & \\
\hline & $\begin{array}{l}\text { User } \\
(\mathrm{N}=24)\end{array}$ & $\begin{array}{l}\text { Non-user } \\
(\mathrm{N}=43)\end{array}$ & $P$ value & $\begin{array}{l}\text { User } \\
(\mathrm{N}=44)\end{array}$ & $\begin{array}{l}\text { Non-user } \\
(\mathrm{N}=73)\end{array}$ & $P$ value \\
\hline Twice & $4(17 \%)$ & $1(2 \%)$ & & $8(18 \%)$ & $4(5 \%)$ & \\
\hline Three times & $2(8 \%)$ & $0(0 \%)$ & & $5(11 \%)$ & $1(1 \%)$ & \\
\hline Four times or more & $1(4 \%)$ & $0(0 \%)$ & & $1(2 \%)$ & $0(0 \%)$ & \\
\hline \multicolumn{7}{|c|}{ Early intervention after initial admission ${ }^{*}$} \\
\hline None & $18(74 \%)$ & $42(98 \%)$ & 0.008 & $31(71 \%)$ & $69(95 \%)$ & 0.001 \\
\hline One time & $3(13 \%)$ & $1(2 \%)$ & & $9(20 \%)$ & $4(5 \%)$ & \\
\hline Twice & $3(13 \%)$ & $0(0 \%)$ & & $4(9 \%)$ & $0(0 \%)$ & \\
\hline Three times & $0(0 \%)$ & $0(0 \%)$ & & $0(0 \%)$ & $0(0 \%)$ & \\
\hline
\end{tabular}

"Early intervention was defined as escalation of oral and intravenous diuretics at the outpatient department or shortened outpatient visit intervals without any hospitalization

Table 2 Outcome measures

\begin{tabular}{|c|c|c|c|c|c|c|}
\hline \multirow[t]{3}{*}{ Variables } & \multicolumn{3}{|c|}{ Propensity score-matched cohort } & \multicolumn{3}{|l|}{ Entire cohort } \\
\hline & \multicolumn{3}{|c|}{ Rehospitalized patients } & \multicolumn{3}{|c|}{ Rehospitalized patients } \\
\hline & $\begin{array}{l}\text { User } \\
(\mathrm{N}=24)\end{array}$ & $\begin{array}{l}\text { Non-user } \\
(\mathrm{N}=43)\end{array}$ & $P$ value & $\begin{array}{l}\text { User } \\
(\mathrm{N}=44)\end{array}$ & $\begin{array}{l}\text { Non-user } \\
(\mathrm{N}=73)\end{array}$ & P value \\
\hline BNP value at rehospitalization $(\mathrm{pg} / \mathrm{ml})$ & $763(516-1428)$ & $628(435-1502)$ & 0.707 & $984(512-1493)$ & $680(376-1580)$ & 0.403 \\
\hline The maximum daily dose of intravenous furosemide $(\mathrm{mg})$ & $15(10-35)$ & $10(0-25)$ & 0.275 & $20(10-40)$ & $10(0-40)$ & 0.192 \\
\hline Patients requiring intravenous inotropes, $\mathrm{n}(\%)$ & $13(30 \%)$ & $21(29 \%)$ & 1.000 & $13(30 \%)$ & $21(29 \%)$ & 1.000 \\
\hline The length of rehospitalization (day) & $15.5(12.3-26)$ & $15(11-27)$ & 0.958 & $14.5(12-25.3)$ & $19(13-34)$ & 0.242 \\
\hline In-hospital mortality, n (\%) & $1(4.2 \%)$ & $4(9.3 \%)$ & 0.647 & $3(6.8 \%)$ & 7 (9.6\%) & 0.741 \\
\hline
\end{tabular}

regimen at outpatient. Second, the continuation and quality of the self-management system were not assessed. Third, data on practices at unplanned visits were not analyzed. Finally, data from unplanned visits to other health centers were not collected. Fourth, additional factors beyond HF severity and clinical practice, such as interphysician and patient thresholds for hospitalization and environmental factors of the patients, may have contributed to rehospitalization.

\section{Abbreviations}

BNP: Brain natriuretic peptides; HF: Heart failure; IQR: Interquartile range; PS: Propensity scores.

\section{Supplementary Information}

The online version contains supplementary material available at https://doi. org/10.1186/s13104-021-05864-6.

Additional file 1. Method. Details of self-care management system and propensity score matching.

\section{Acknowledgements}

Not applicable.

\section{Authors' contributions}

Conceptualization: EN, TKA. Data curation: EN, NT. Data collection: TKU, KK, SN, TH, YM, YY, YH, TH. Formal analysis: EN, TKato. Writing—original draft: TKato. Writing-made critical review: TKuriyama, KK, SN, TH, YM, YY, YH, TH, MI. Supervision: Ml. All authors have read and approved the final manuscript.

Funding

The authors had no funding regarding this manuscript.

\section{Availability of data and materials}

The data analyzed during this study are not publicly available as the secondary use of the qualitative data is limited by ethical committee. Questions about access to deidentified data should be addressed to the corresponding author.

\section{Declarations}

\section{Ethical approval and consent to participate}

The study protocol was approved by the Institutional Review Board of Kitano Hospital (P190600100). Written informed consent was not obtained because of the retrospective nature of the study. We disclosed all study details to the public using an opt-out method and clearly informed the patients of their right to refuse enrollment. The ethics committee approved this procedure.

Consent to publication

Not applicable. 


\section{Competing interests}

Eisaku Nakane received research grants from Bayer Yakuhin, Ltd. and Nippon Shinyaku Co., Ltd., and a scholarship grant from Nihon Medi-Physics Co., Ltd.

\section{Author details}

${ }^{1}$ Cardiovascular Center, Tazuke Kofukai Medical Research Institute, Kitano Hospital, 2-4-20 Ohgimachi, Kita-ku, Osaka City 530-8480, Japan. ${ }^{2}$ Department of Cardiovascular Medicine, Graduate School of Medicine, Kyoto University, 54 Shogoin Kawahara-cho, Sakyo-ku, Kyoto 606-8507, Japan.

Received: 19 July 2021 Accepted: 29 November 2021

Published online: 18 December 2021

\section{References}

1. Riegel B, Moser DK, Anker SD, Apple LJ, Dunbar SB, Grady KL, et al. State of the science: promoting self-care in persons with heart failure: a scientific statement from the American Heart Association. Circulation. 2009;120:1141-63.

2. Jurgens CY, Hoke L, Byrnes J, Riegel B. Why do delay responding to heart failure symptoms? Nurs Res. 2009;58:274-82.

3. Murad K, Goff DC Jr, Morgan TM, Burke GL, Bartz TM, Kizer JR, et al. Burden of comorbidities and functional and cognitive impairments in elderly patients at the initial diagnosis of heart failure and their impact on total mortality: the cardiovascular health study. JACC Heart Fail. 2015;3:542-50.

4. Nakane E, Kato T, Tanaka N, Kuriyama T, Kimura K, Nishiwaki S, Hamaguchi T, Morita Y, Yamaji Y, Haruna Y, Haruna T, Inoko M. Association of the induction of a self-care management system with 1-year outcomes in patients hospitalized for heart failure. J Cardiol. 2021;77(1):48-56.

5. Setoguchi S, Stevenson LW, Schneeweiss S. Repeated hospitalizations predict mortality in the community population with heart failure. Am Heart J. 2007;154:260-6.

6. Lee DS, Austin PC, Stukel TA, Alter DA, Chong A, Parker JD, et al. "Dosedependent" impact of recurrent cardiac events on mortality in patients with heart failure. Am J Med. 2009;122:162-9.

7. Solomon SD, Dobson J, Pocock S, Skali H, McMurray JJ, Granger CB, et al. Influence of nonfatal hospitalization for heart failure on subsequent mortality in patients with chronic heart failure. Circulation. 2007;116:1482-7.

8. Akita K, Kohno T, Kohsaka S, Shiraishi Y, Nagatomo Y, Goda A, et al. Prognostic impact of previous hospitalization in acute heart failure patients. Circ J. 2019;83:1261-8.

9. Su K, Kato T, Toyofuku M, Morimoto T, Yaku H, Inuzuka Y, Tamaki Y, Ozasa N, Yamamoto E, Yoshikawa Y, Motohashi Y, Watanabe H, Kitai T, Taniguchi R, Iguchi M, Kato M, Nagao K, Kawai T, Komasa A, Nishikawa R, Kawase Y, Morinaga T, Jinnai T, Kawato M, Sato Y, Kuwahara K, Tamura T, Kimura T. KCHF registry investigators. Association of previous hospitalization for heart failure with increased mortality in patients hospitalized for acute decompensated heart failure. Circ Rep. 2019;1(11):517-24.

10. Morimoto T, Sakuma M, Matsui K, Kuramoto N, Toshiro J, Murakami J, Fukui T, Saito M, Hiraide A, Bates DW. Incidence of adverse drug events and medication errors in Japan: the JADE study. J Gen Intern Med. 2011;26(2):148-53.

11. Yaku H, Kato T, Morimoto T, Inuzuka Y, Tamaki Y, Ozasa N, Yamamoto E, Yoshikawa Y, Kitai T, Kato M, Ikeda T, Furukawa Y, Nakagawa Y, Sato Y, Kuwahara K, Kimura T. Risk factors and clinical outcomes of functional decline during hospitalisation in very old patients with acute decompensated heart failure: an observational study. BMJ Open. 2020;10(2): e032674

12. Soundarraj D, Singh V, Satija $V$, Thakur RK. Containing the cost of heart failure management: a focus on reducing readmissions. Heart Fail Clin 2017;13:21-8

\section{Publisher's Note}

Springer Nature remains neutral with regard to jurisdictional claims in published maps and institutional affiliations.

Ready to submit your research? Choose BMC and benefit from:

- fast, convenient online submission

- thorough peer review by experienced researchers in your field

- rapid publication on acceptance

- support for research data, including large and complex data types

- gold Open Access which fosters wider collaboration and increased citations

- maximum visibility for your research: over $100 \mathrm{M}$ website views per year

At BMC, research is always in progress.

Learn more biomedcentral.com/submissions 